\title{
Establishment of Tissue Culture System of Actinidia deliciosa Cultivar "Guichang"
}

\author{
Weimin Zhong $\mathbb{D}^{1}{ }^{1}$ Junliang Zhou $\mathbb{D}^{1},{ }^{1}$ Dongmei Tang $\mathbb{D}^{1},{ }^{1}$ Yaxin Huang, ${ }^{2}$ Futao Liu, ${ }^{1}$ \\ Min Zhang, ${ }^{1}$ Guoli Wang, ${ }^{2}$ Sufang $\mathrm{Wu}^{2}{ }^{2}$ Yue He, ${ }^{2}$ and Jingwen Tang ${ }^{2}$ \\ ${ }^{1}$ Institute of Fruit Science, Guizhou Academy of Agricultural Sciences, Guiyang 550006, China \\ ${ }^{2}$ Agricultural Bureau of Xiuwen County, Xiuwen 550200, China \\ Correspondence should be addressed to Dongmei Tang; tdmemail@126.com
}

Received 11 November 2021; Revised 30 November 2021; Accepted 2 December 2021; Published 16 December 2021

Academic Editor: Wenneng Wu

Copyright ( 92021 Weimin Zhong et al. This is an open access article distributed under the Creative Commons Attribution License, which permits unrestricted use, distribution, and reproduction in any medium, provided the original work is properly cited.

\begin{abstract}
In order to breed virus-free plantlets of the kiwifruit cultivar "Guichang," which belongs to Actinidia deliciosa, in this study, stem segments with buds were used as explants, the establishment of a tissue culture rapid propagation system was carried out, and then the virus status of tissue culture plantlets was detected via the real-time reverse transcription-polymerase chain reaction (RT-qPCR) method. The tissue culture rapid propagation system proved that the contamination and browning rates could be controlled below $20 \%$ and the survival rate could be exceeded by $70 \%$ when the single bud stem segment of "Guichang" kiwifruit was sterilized with $70 \%$ alcohol for $30-60 \mathrm{~s}$ and $15 \% \mathrm{NaClO}$ for $15 \mathrm{~min}$, respectively. Meanwhile, we screened the hormone concentration to get better results, and the appropriate medium for adventitious bud induction was MS + 6-BA (1.0 mg/L) + IBA $(0.2 \mathrm{mg} / \mathrm{L})$; for proliferation, it was MS + 6-BA $(1.0 \mathrm{mg} / \mathrm{L})+\mathrm{IBA}(0.1 \mathrm{mg} / \mathrm{L})$; and for rooting, it was $1 / 2 \mathrm{MS}+\mathrm{IBA}(0.3 \mathrm{mg} / \mathrm{L})$, and the efficiency of induction, proliferation, and rooting could reach $74.07 \%, 79.63 \%$, and $85.18 \%$, respectively. In addition, the RT-qPCR results demonstrated that the infection rate of 9 viruses: apple stem grooving virus (ASGV), cucumber mosaic virus (CMV), Actinidia virus X (AVX), cucumber necrosis virus (CNV), ribgrass mosaic virus (RMV), citrus leaf blotch virus (CLBV), Actinidia virus B (AcVB), Pelargonium zonate spot virus (PZSV), and cherry leaf roll virus (CLRV) in the "Guichang" kiwifruit tissue culture plantlets was 0 . This study could lay a foundation for the production of "Guichang" kiwifruit tissue culture seedlings, and the medium formula provided in this study was useful for the industrial rapid propagation of "Guichang" plantlets.
\end{abstract}

\section{Introduction}

Kiwifruit (Actinidia spp.), an important and economically substantial fruit in China, has long been known as "the king of fruits" because of its high vitamin C content and balanced nutritional composition of minerals and other health-promoting metabolites $[1,2]$. Kiwifruit cultivar "Guichang" (Actinidia deliciosa var. deliciosa), one excellent cultivar with the characteristics of excellent quality, beautiful appearance, strong resistance, and high yields from wild resources, developed by the Institute of Fruit Science, Guizhou Academy of Agricultural Sciences in 1979, has become the main cultivar in Guizhou province [3]. By 2018, the cultivation area of "Guichang" kiwifruit in Guizhou was nearly 16,000 hectares.
As most species of Actinidia are dioecious and have a long juvenile period, it is difficult to identify the gender of young plants $[4,5]$. Due to the limited number of branches, the traditional cutting and grafting methods make it difficult to cultivate large numbers of plantlets in a short time. Therefore, the tissue culture had gradually become the main method to produce numerous plantlets rapidly, which had the advantages of stable inheritance, maintaining good traits, no time and space restrictions, and a high reproduction coefficient. Since the 1970s, tissue culture rapid propagation has become an important breeding method. Recently, more and more research studies on the establishment of kiwifruit rapid propagation systems have been performed [6-9]. However, in the process of in vitro rapid propagation of kiwifruit, serious browning and diseases of explants in 
primary culture have become a major obstacle $[10,11]$. In recent years, some literature has reported that many viruses, including apple stem grooving virus (ASGV), cucumber mosaic virus (CMV), Actinidia virus X (AVX), cucumber necrosis virus (CNV), ribgrass mosaic virus (RMV), Actinidia virus $B(\mathrm{AcVB})$, Actinidia virus $A(\mathrm{AcVA})$, Actinidia virus 1 (AcV-1), alfalfa mosaic virus (AMV), cherry leaf roll virus (CLRV), tomato necrotic spot associated virus (TNSaV), tomato zonate spot virus (TZSV), Pelargonium zonate spot virus (PZSV), citrus leaf blotch virus (CLBV), Actinidia chlorotic ringspot-associated virus (AcCRaV), turnip vein clearing virus (TVCV), and Actinidia seed-borne latent virus (ASbLV), can infect kiwifruit plants through pollen, grafting, or artificial inoculation [12-19]. Once infected, viruses cause a detrimental effect on the growth and development of kiwifruit plants, and the fruits will be deformed and the yields will be reduced, with huge economic loss. However, the traditional cutting and grafting methods had a good chance of spreading viruses to the other branches and thus expanding the spread of viral diseases. Therefore, it is urgent to develop the rapid propagation technology of "Guichang" kiwifruit.

In order to breed virus-free plantlets of "Guichang" kiwifruit, in this study, the establishment of a tissue culture rapid propagation system was carried out, and then detected the virus status via the real-time reverse transcription-polymerase chain reaction (RT-qPCR) method. To our knowledge, this is the first report on the rapid production of "Guichang" kiwifruit tissue culture plantlets. This study provides scientific guidance for large-scale factory production and boosts the healthy development of the kiwifruit industry in China.

\section{Materials and Methods}

2.1. Experimental Materials. The materials were taken from the kiwifruit demonstration area (north latitude: 26.816339, east longitude: 106.492149) of Gubao township, Xiuwen county, Guizhou province, China, in June 2015. Plants with robust growth and good comprehensive performance were selected as the sampled parent plants. New shoots were removed from the tops with the base semilignified, and leaf blades that had not fully developed were used as explants for in vitro culture. The young leaves of the parent plant were hydropically cultured to accelerate budding, and the young leaves cultured by tissue culture were taken as test materials for virus detection.

2.2. Sterilization of the Explants. For sterilization of the explants, the petioles, which were removed from the leaves, were cut into $5-6 \mathrm{~cm}$ long pieces, rinsed with tap water several times, soaked in detergent water for $30 \mathrm{~min}$, and rinsed with tap water for $1-2 \mathrm{~h}$. Then, the explants were soaked with $70 \%$ alcohol for 10,30 , and 60 s, respectively, and soaked with $15 \%$ sodium hypochlorite $(\mathrm{NaClO})$ for 10 , 15 , and $20 \mathrm{~min}$, respectively. After that, the explants were washed with sterile water 3-4 times, sucked dry with sterile paper, cut into $1.5-2.0 \mathrm{~cm}$ segments with a single bud, and inoculated on Murashige and Skoog (MS) culture medium without adding hormones. After 20 days of inoculation with an illumination intensity of $2000 \mathrm{Lx}$ and at $25^{\circ} \mathrm{C}$ with a light/ dark cycle of $16 / 8 \mathrm{~h}$, the contamination, browning, and survival rates were calculated as the following equations:

Contamination rate $(\%)=$ (number of browning explants/number of inoculated explants $) \times 100$

Browning rate $(\%)=$ (number of contaminated explants/number of inoculated explants $) \times 100$

Survival rate $(\%)=$ (number of the survival explants/ number of inoculated explants $) \times 100$

2.3. Proliferation Culture. The disinfected explants were inoculated on the MS culture medium with 6-benzyl aminopurine (6-BA, $0 \mathrm{mg} / \mathrm{L})+$ indolebutyric acid (IBA, $0.2 \mathrm{mg} / \mathrm{L}), 6-\mathrm{BA}(0.5 \mathrm{mg} / \mathrm{L})+\mathrm{IBA}(0.2 \mathrm{mg} / \mathrm{L}), 6-\mathrm{BA}(1.0 \mathrm{mg} /$ $\mathrm{L})+\mathrm{IBA}(0.2 \mathrm{mg} / \mathrm{L}), 6-\mathrm{BA}(1.5 \mathrm{mg} / \mathrm{L})+\mathrm{IBA}(0.2 \mathrm{mg} / \mathrm{L})$, and 6-BA $(2.0 \mathrm{mg} / \mathrm{L})+\mathrm{IBA}(0.2 \mathrm{mg} / \mathrm{L})$, respectively. The inducement rate of the axillary buds was calculated after 30 days of inoculation with an illumination intensity of $2000 \mathrm{Lx}$, a temperature of $25^{\circ} \mathrm{C}$, and light/dark cycles of $16 / 8 \mathrm{~h}$ : inducement rate $(\%)=$ (number of explants in axillary bud germination/number of inoculated explants $) \times 100$.

For subculture, the sterile new single shoots that grow on the primary culture medium were cut into $0.5-1.0 \mathrm{~cm}$ long stem segments and then inoculated on the proliferation MS culture medium with 6-BA $(0 \mathrm{mg} / \mathrm{L})+\mathrm{IBA}(0.1 \mathrm{mg} / \mathrm{L}), 6-\mathrm{BA}$ $(0.5 \mathrm{mg} / \mathrm{L})+\mathrm{IBA} \quad(0.1 \mathrm{mg} / \mathrm{L}), \quad 6-\mathrm{BA} \quad(1.0 \mathrm{mg} / \mathrm{L})+\mathrm{IBA}$ $(0.1 \mathrm{mg} / \mathrm{L}), 6-\mathrm{BA}(1.5 \mathrm{mg} / \mathrm{L})+\mathrm{IBA}(0.1 \mathrm{mg} / \mathrm{L})$, and $6-\mathrm{BA}$ $(2.0 \mathrm{mg} / \mathrm{L})+$ IBA $(0.1 \mathrm{mg} / \mathrm{L})$, respectively. The growth of tube plantlets was observed, and the proliferation coefficients were calculated after 30 days of inoculation with an illumination intensity of $2000 \mathrm{Lx}$, a temperature of $25^{\circ} \mathrm{C}$, and light/dark cycles of 16/8 h.

Proliferation rate $(\%)=$ (number of regeneration buds/number of inoculated buds) $\times 100$

Proliferation coefficients $=$ number of regeneration buds/number of inoculated buds

2.4. Rooting and Transplantation Culture. The sterile new single shoots produced by adventitious buds were cut into $0.5-1.0 \mathrm{~cm}$ long stem segments and then inoculated on the rooting culture medium (1/2 MS culture medium) with 0.1 , $0.3,0.5$, and $0.7 \mathrm{mg} / \mathrm{L}$ of IBA, respectively. The rooting rate and root number were counted after 30 days of inoculation with an illumination intensity of $2000 \mathrm{Lx}$, a temperature of $25^{\circ} \mathrm{C}$, and light/dark cycles of $16 / 8 \mathrm{~h}$ : rooting rate $(\%)=$ (number of rooting explants/number of inoculated explants) $\times 100$.

Tissue culture plantlets, with a height of more than $4 \mathrm{~cm}$, 3-5 leaves, and more than 3 roots, were selected and placed into the greenhouse $\left(23-25^{\circ} \mathrm{C}\right.$ and $90 \%$ relative humidity $(\mathrm{RH}))$ to harden the plantlets for 7 days, then the plantlets were transplanted into the paper cups with the matrix containing perlite, vermiculite, and peat $(1: 1: 2, \mathrm{v} / \mathrm{v})$ and then transferred the paper cups into the greenhouse with 
natural lighting, a temperature of $23-25^{\circ} \mathrm{C}$, and $\mathrm{RH}$ to reduce the gradient from $90 \%$ to indoor humidity. Meanwhile, the plantlets were regularly irrigated with the 1/8 MS nutrient solution and a pesticide, such as carbendazim, that prevents young plants from rotting. The plantlets were grown for about 30 days, and then the survival rate was calculated using the following equation: survival rate $(\%)=($ number of the transplanting survival/number of transplanting explants) $\times$ 100.

2.5. RNA Extraction and RT-qPCR Detection. A total of 9 kinds of viruses, including ASGV, CMV, AVX, CNV, RMV, CLBV, AcVB, PZSV, and CLRV, were detected via the RT-qPCR method $[18,19]$. The RNA of the "Guichang" kiwifruit leaves was extracted using the total RNA extraction kit (Qiagen, Hilden, Germany). The purity $\left(\mathrm{OD}_{260} / \mathrm{OD}_{280}\right)$ and concentration of the extracted RNA were detected by an ultraviolet spectrophotometer (Beckman Instruments, Inc., Fullerton, CA). RNA was reverse-transcribed using a cDNA kit (TaKaRa, Dalian, China) according to the manufacturer's instructions. The primers used for RT-qPCR amplification are listed in Table 1. The RT-qPCR amplification was carried out according to the method reported by Huang et al. [2]. After that, the electrophoresis of the RT-qPCR products was performed with a $1.2 \%$ agarose gel (Bio Tech Corporation, Beijing, China).

2.6. Statistical Analysis. SPSS 17.0 (SPSS Inc., Chicago, USA) was used for statistical analysis. Statistical analysis was conducted by ANOVA with software SPSS 17.0 (SPSS Inc., Chicago, USA). Different lowercase letters indicate a significant difference $(p<0.05)$ among different treatment groups.

\section{Results}

3.1. Sterilization of the Explants. Table 2 shows that, with the prolonged sterilization time of $70 \%$ alcohol and $15 \% \mathrm{NaClO}$, the contamination rate of explants gradually decreased while the browning rate gradually increased, and the survival rate increased first and then decreased. Meanwhile, Table 2 shows that the contamination and browning rates could be controlled below $20 \%$ and the survival rate could be exceeded by $70 \%$ when the single bud stem segments of "Guichang" kiwifruit were sterilized with $70 \%$ alcohol for $30-60 \mathrm{~s}$ and $15 \% \mathrm{NaClO}$ for $15 \mathrm{~min}$, respectively.

3.2. Induction, Proliferation, and Rooting Culture. As shown in Table 3, with the increase of 6-BA concentration, the germination rate of axillary buds first increased and then decreased; especially, using $\mathrm{MS}+6-\mathrm{BA}(1.0 \mathrm{mg} / \mathrm{L})+\mathrm{IBA}$ $(0.2 \mathrm{mg} / \mathrm{L})$ as the induction medium, the inducement rate reached $74.07 \%$ and the plantlets were robust with almost no callus at the base.

Table 4 shows that all the tested concentrations of 6-BA could enhance the proliferation rate; especially, using MS + 6-BA $(1.0 \mathrm{mg} / \mathrm{L})+\mathrm{IBA}(0.1 \mathrm{mg} / \mathrm{L})$ as the proliferation medium, the proliferation rate and proliferation coefficient reached the highest values of $79.63 \%$ and 5.06 , respectively. Meanwhile, the plants were robust with green leaves and longer internodes.

Table 5 shows that all the tested concentrations of IBA could enhance the rooting rate, especially taking $1 / 2$ MS + IBA $(0.3 \mathrm{mg} / \mathrm{L})$ as the optimum rooting medium, the rooting rate and average rooting number were $85.18 \%$ and 4.90 , respectively, and the rooting number was $2-6$ with more and longer fibrous roots and basically no callus. After that, the tissue culture plantlets with a height of more than $4 \mathrm{~cm}, 3-5$ leaves, and more than 3 roots were selected and placed into the greenhouse. The survival rate exceeded $90 \%$.

3.3. Virus Detection. A total of 9 kinds of viruses in tissue culture plantlets, including ASGV, CMV, AVX, CNV, RMV, CLBV, AcVB, PZSV, and CLRV, were detected via the RT-qPCR method, and the results (Figure 1) demonstrated that the infection rate of 9 kinds of viruses in tissue culture plantlets was 0 . Therefore, the in vitro tissue culture rapid propagation system established in this study could obtain the virus-free plantlets of "Guichang" kiwifruit.

\section{Discussion}

China is the major source of wild kiwifruit and the world's largest producer and planting area [20]. It has an important significance to study the rapid propagation technology of kiwifruit, which is helpful to promote its development. In the sterilization process of in vitro rapid propagation, many scholars used alcohol and mercury chloride as the disinfecting agents, while only a few scholars used alcohol and $\mathrm{NaClO}[20,21]$. In this study, the single bud stem segment of the "Guichang" kiwifruit was disinfected with 70\% alcohol and $15 \% \mathrm{NaClO}$, and the results showed that the contamination and browning rates could be controlled below $20 \%$ and the survival rate could be exceeded by $70 \%$ when the single bud stem segment of the Guichang kiwifruit was sterilized with $70 \%$ alcohol for $30-60 \mathrm{~s}$ and $15 \% \mathrm{NaClO}$ for 15 min, respectively.

There are many reports on the combination of plant growth regulators in different stages of tissue culture of kiwifruit, and the selection of appropriate auxin types and concentrations is the key role of plant tissue culture. A previous study found that there are some differences in the morphology of tissue culture plantlets induced by different auxin combinations [21]. Yu et al. [22] and Long et al. [23] successfully established the kiwifruit stem culture using $\mathrm{MS}+6-\mathrm{BA}(1.0 \mathrm{mg} / \mathrm{L})+$ naphthylacetic acid (NAA, $0.1 \mathrm{mg} /$ L) medium. It was also found that different concentrations of plant growth regulators could affect the growth and browning of kiwifruit, and the auxin IBA could delay the synthesis of polyphenols and reduce browning [24-26]. Based on the results of previous literature, this experiment studied the effects of IBA at different concentrations on the induction and proliferation of "Guichang" kiwifruit stem segments. As for the effective buds and proliferation coefficients induced in the first generation, when using 
TABle 1: Primers used for RT-qPCR amplification of 9 viruses.

\begin{tabular}{|c|c|c|c|c|}
\hline No. & Virus & Primers & Primer sequence $\left(5^{\prime}-3^{\prime}\right)$ & Product size $(\mathrm{bp})$ \\
\hline \multirow{2}{*}{1} & \multirow{2}{*}{ ASGV } & $\mathrm{F}$ & CCTGAATTGAAAACCTTTGCTGCCACTT & \multirow{2}{*}{456} \\
\hline & & $\mathrm{R}$ & TAGAAAAACCACACTAACCCGGAAATGC & \\
\hline \multirow{2}{*}{2} & \multirow{2}{*}{ CMV } & $\mathrm{F}$ & CTTTCTCATGGATGCTTCTC & \multirow{2}{*}{855} \\
\hline & & $\mathrm{R}$ & GCCGTAAGCTGGATGGAC & \\
\hline \multirow{2}{*}{3} & \multirow{2}{*}{ AVX } & $\mathrm{F}$ & AAGTCCGCAACACCTACCTG & \multirow{2}{*}{175} \\
\hline & & $\mathrm{R}$ & GGACAGACGATAGCAGCCTT & \\
\hline \multirow{2}{*}{4} & \multirow{2}{*}{$\mathrm{CNV}$} & $\mathrm{F}$ & AAGGGTAAGGATGGTGAGGA & \multirow{2}{*}{587} \\
\hline & & $\mathrm{R}$ & TTTGGTAGGTTGTGGAGTGC & \\
\hline \multirow{2}{*}{5} & \multirow{2}{*}{ RMV } & $\mathrm{F}$ & AGACAGCAATTCTCAAACTTGT & \multirow{2}{*}{223} \\
\hline & & $\mathrm{R}$ & CGGTCGCATCATCAACAC & \\
\hline \multirow{2}{*}{6} & \multirow{2}{*}{ CLBV } & $\mathrm{F}$ & AGCCATAGTTGAACCATTCCTC & \multirow{2}{*}{425} \\
\hline & & $\mathrm{R}$ & GCAGATCATTCACCACATGC & \\
\hline \multirow{2}{*}{7} & \multirow{2}{*}{$\mathrm{AcVB}$} & $\mathrm{F}$ & AATTCGGACCACTCCTGAGGC & \multirow{2}{*}{529} \\
\hline & & $\mathrm{R}$ & CTCATTCTCCAMCCRCARAAGAG & \\
\hline \multirow{2}{*}{8} & \multirow{2}{*}{ PZSV } & $\mathrm{F}$ & GATAAATTCAGAGCTCTCGG & \multirow{2}{*}{997} \\
\hline & & $\mathrm{R}$ & ATCTCTGCAGATTGTGTTCC & \\
\hline \multirow{2}{*}{9} & \multirow{2}{*}{ CLRV } & $\mathrm{F}$ & TGGCGACCGTGTAACGGCA & \multirow{2}{*}{416} \\
\hline & & $\mathrm{R}$ & GTCGGAAAGATTACGTAAAAGG & \\
\hline
\end{tabular}

TABLE 2: Comparison of sterilization effects of different disinfection treatments.

\begin{tabular}{|c|c|c|c|c|c|}
\hline \multirow{2}{*}{ Treatment } & \multicolumn{2}{|c|}{ Disinfection } & \multirow{2}{*}{ Contamination rate $(\%)^{*}$} & \multirow{2}{*}{ Browning rate $(\%)^{*}$} & \multirow{2}{*}{ Survival rate $(\%)^{*}$} \\
\hline & $70 \%$ alcohol (s) & $15 \% \mathrm{NaClO}(\mathrm{min})$ & & & \\
\hline 1 & & 10 & $74.07 \mathrm{a}$ & $7.41 \mathrm{c}$ & $18.52 \mathrm{e}$ \\
\hline 2 & 10 & 15 & $46.30 \mathrm{~b}$ & $22.22 b c$ & $31.48 \mathrm{bcde}$ \\
\hline 3 & & 20 & $25.93 \mathrm{cde}$ & $44.44 \mathrm{a}$ & 29.63de \\
\hline 4 & & 10 & $40.74 \mathrm{bc}$ & $11.11 \mathrm{c}$ & $48.15 b c d$ \\
\hline 5 & 30 & 15 & $14.81 \mathrm{def}$ & $9.30 c$ & $75.93 a$ \\
\hline 6 & & 20 & $11.11 \mathrm{ef}$ & $29.63 b$ & $59.26 \mathrm{ab}$ \\
\hline 7 & & 10 & $29.63 \mathrm{~cd}$ & $18.52 \mathrm{bc}$ & $51.85 \mathrm{bc}$ \\
\hline 8 & 60 & 15 & $9.30 \mathrm{f}$ & $18.52 \mathrm{bc}$ & $72.22 \mathrm{a}$ \\
\hline 9 & & 20 & $7.41 \mathrm{f}$ & $53.70 \mathrm{a}$ & $38.89 \mathrm{bcde}$ \\
\hline
\end{tabular}

* Different lowercase letters indicate a significant difference $(p<0.05$ among different treatment groups.

TABLE 3: Effect of different concentrations of 6-BA on inducing axillary bud sprouting.

\begin{tabular}{lcccc}
\hline Treatment & \multicolumn{2}{c}{$\begin{array}{c}\text { Concentration } \\
(\mathrm{mg} / \mathrm{L})\end{array}$} & Inducement rate $(\%)^{*}$ & Growth conditions \\
& $6-\mathrm{BA}$ & IBA & $25.93 \mathrm{c}$ & Plantlets robust, no callus at the base \\
1 & 0 & 0.2 & $42.59 \mathrm{bc}$ & Plantlets robust, almost no callus at the base \\
3 & 0.5 & 0.2 & $74.07 \mathrm{a}$ & Plantlets robust, almost no callus at the base \\
4 & 1.0 & 0.2 & $53.70 \mathrm{ab}$ & Plantlets robust, a few small clusters of calluses at the base \\
5 & 1.5 & 0.2 & $42.59 \mathrm{c}$ & Plantlets robust, small clusters of calluses at the base \\
\hline
\end{tabular}

* Different lowercase letters indicate a significant difference $(p<0.05)$ among different treatment groups.

$\mathrm{MS}+6-\mathrm{BA}(1.0 \mathrm{mg} / \mathrm{L})+\mathrm{IBA}(0.2 \mathrm{mg} / \mathrm{L})$ as the optimum induction medium, the inducement rate was $74.07 \%$ and the plantlets were almost robust with no callus at the base (Figure 2(a)). Meanwhile, using MS + 6-BA (1.0 mg/L) + IBA $(0.1 \mathrm{mg} / \mathrm{L})$ as the optimum proliferation medium, the proliferation rate reached $79.63 \%$, the proliferation coefficient was greater than 5 , and the plants were robust with green leaves and longer internodes (Figure 2(b)). MS medium is an important substrate for plant tissue culture, and the selection of an appropriate medium type is crucial to the success or failure of plant tissue culture [27]. Regarding the root culture of kiwifruit, a large body of literature showed that 1/2 MS medium with a low salt content is more conducive to the rooting of kiwifruit tissue culture plantlets [28]. Meanwhile, the use of auxins in MS medium for in vitro rooting stage has also been reported by many other researchers [29]. In addition, it has also been reported that IBA induced lateral rooting better than IAA and NAA [20]. In this study, using $1 / 2 \mathrm{MS}+\mathrm{IBA}(0.3 \mathrm{mg} / \mathrm{L})$ as the optimum rooting medium, the rooting rate and average rooting number reached $85.18 \%$ 


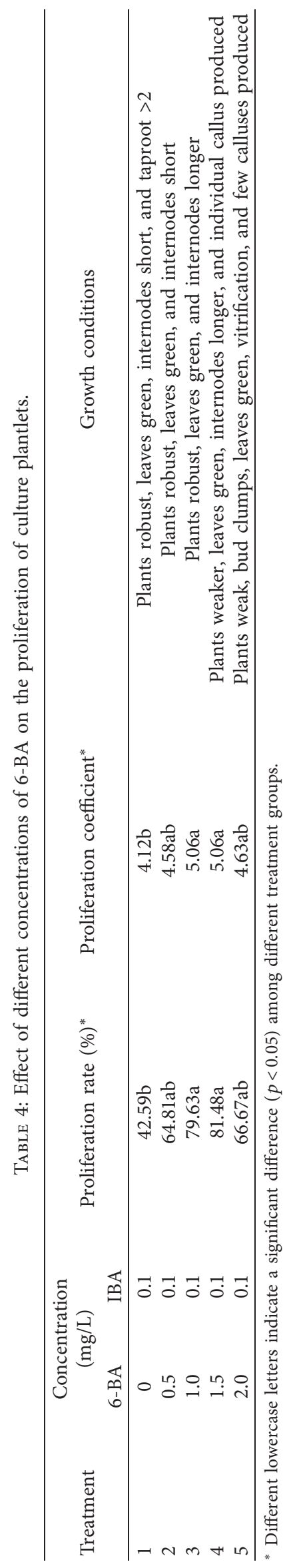


TABLE 5: Effect of different concentrations of IAA on rooting of culture plantlets.

\begin{tabular}{lcccc}
\hline Treatment & $\begin{array}{c}\text { IBA concentration }(\mathrm{mg} / \\
\mathrm{L})\end{array}$ & $\begin{array}{c}\text { Rooting rate } \\
(\%)^{*}\end{array}$ & $\begin{array}{c}\text { Average rooting } \\
\text { number* }\end{array}$ & Rooting situation \\
\hline 1 & 0 & $42.59 \mathrm{c}$ & $3.35 \mathrm{~d}$ & $2-5$ roots, a small amount of fibrous root, and no callus \\
2 & 0.1 & $81.48 \mathrm{ab}$ & $4.13 \mathrm{bc}$ & $2-5$ roots, more fibrous roots, and no callus \\
3 & 0.3 & $85.18 \mathrm{a}$ & $4.90 \mathrm{a}$ & $2-6$ roots, more and longer fibrous roots, and basically \\
& & & no callus \\
5 & 0.5 & $85.18 \mathrm{a}$ & $4.48 \mathrm{ab}$ & $2-6$ roots, few fibrous roots, and small callus at base \\
5 & 0.7 & $62.96 \mathrm{~b}$ & $3.78 \mathrm{~cd}$ & $2-5$ roots, no fibrous roots, and few calluses at base \\
\hline
\end{tabular}

${ }^{*}$ Different lowercase letters indicate a significant difference $(p<0.05)$ among different treatment groups.

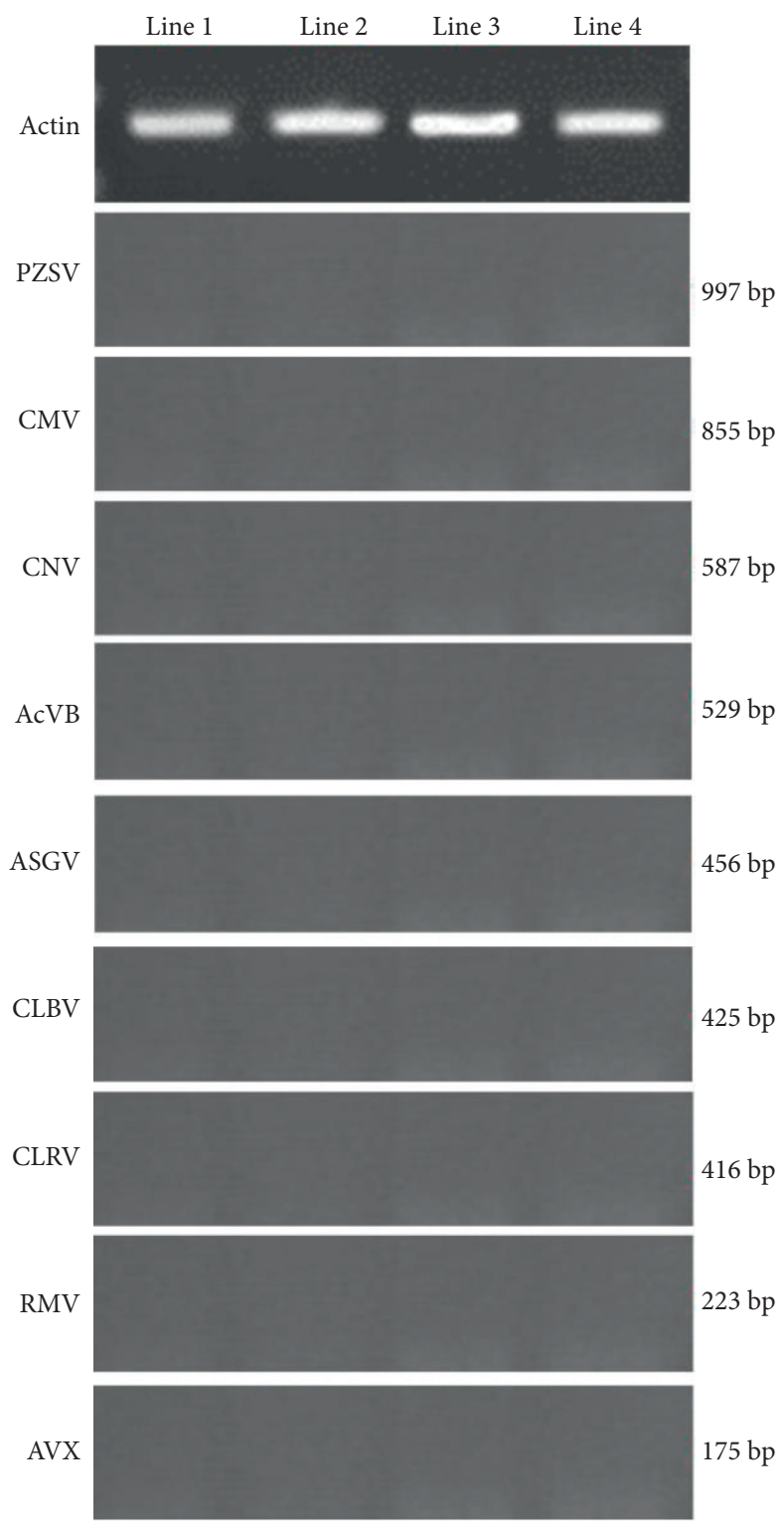

FIgURE 1: The electrophoresis results of the RT-qPCR products.

and 4.90, respectively, and the rooting number was 2-6 with more and longer fibrous roots and basically no callus (Figure 2(c)). After that, the tissue culture plantlets were transplanted into the greenhouse, and the survival rate exceeded $90 \%$ (Figure 2(d)).
Virus disease is a kind of disease with a long incubation period and a great production so hidden trouble. In recent years, many works of literature have reported that kiwifruit virus diseases, especially the pathogenic viruses CLRV and PZSV, which can be spread through pollen, grafting, or 


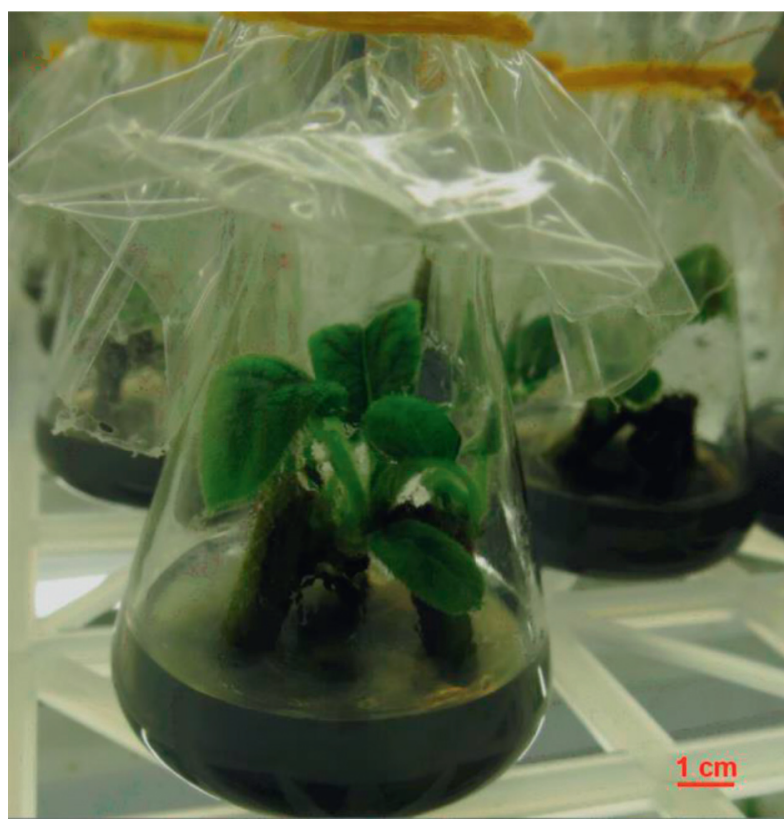

(a)

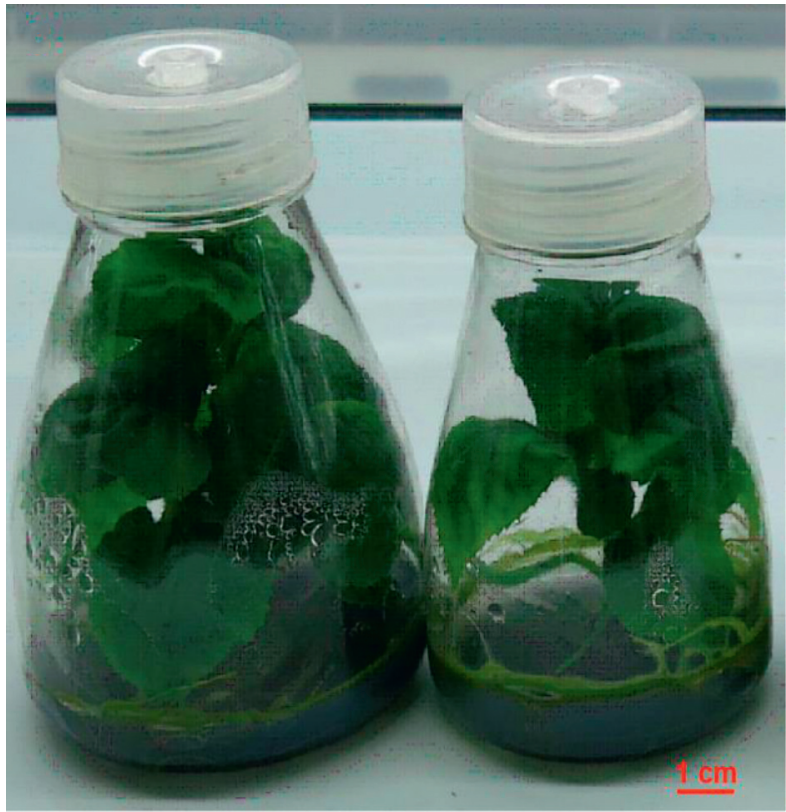

(c)

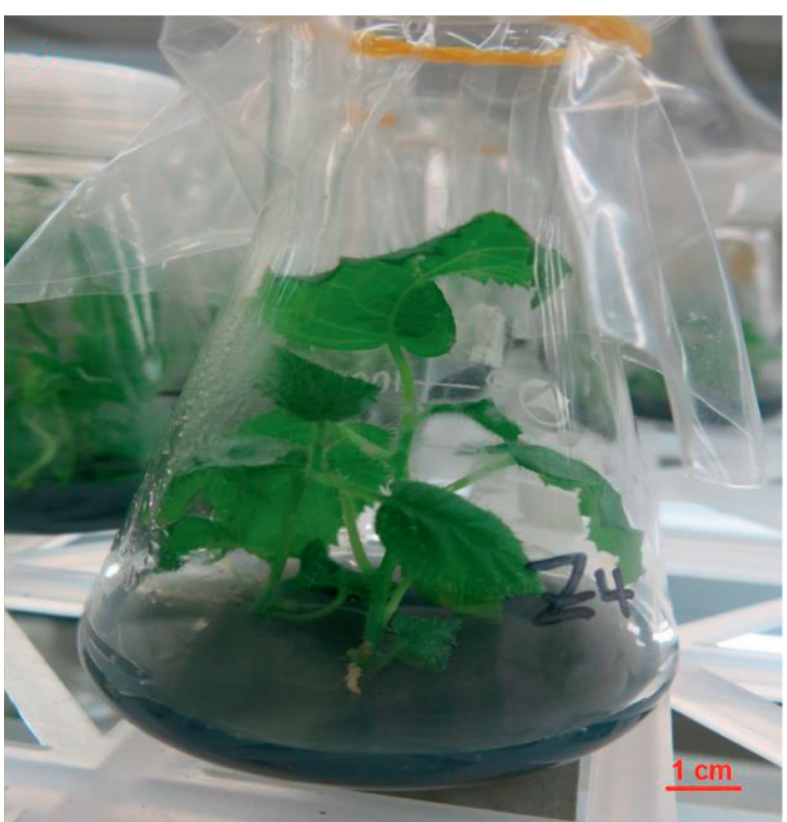

(b)

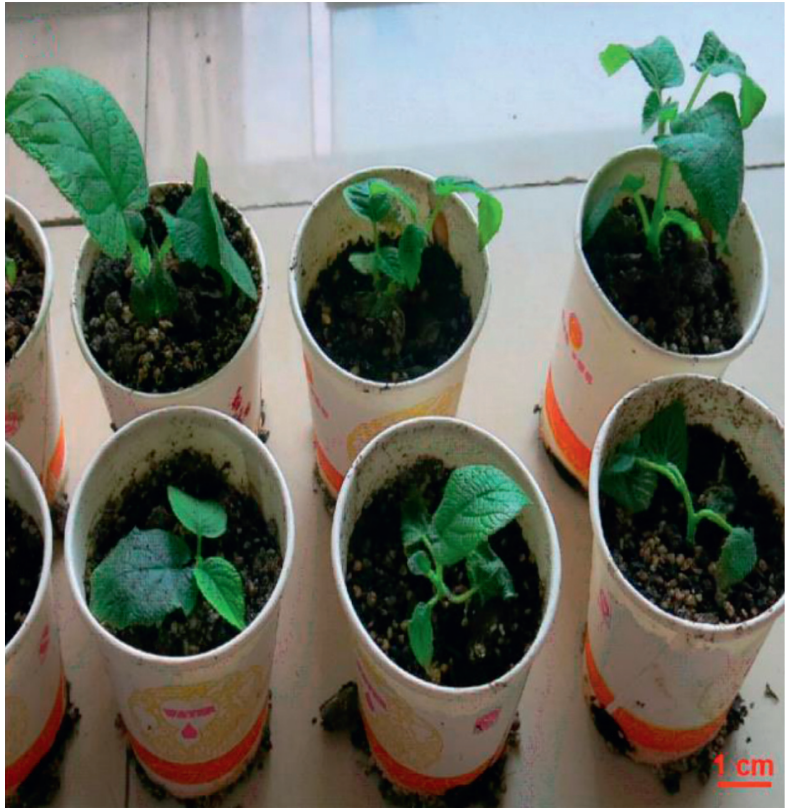

(d)

FIGURE 2: The rapid in vitro propagation of "Guichang" kiwifruit by tissue culture techniques. (a) Induction culture, (b) proliferation culture, (c) rooting culture, and (d) transplantation culture.

mechanical inoculation, are common in preserved kiwifruit germplasm resources and cultivated kiwifruit plants [30, 31]. Meanwhile, during the cultivation and promotion of "Guichang" kiwifruit for several decades, the virus disease in the main "Guichang" kiwifruit producing areas seriously affected the fruit appearance and commodity value, causing huge economic losses to the kiwifruit industry. In this study, a total of 9 kinds of viruses, including ASGV, CMV, AVX, CNV, RMV, CLBV, AcVB, PZSV, and CLRV, in tissue culture plantlets were detected via the RT-qPCR method, and the results demonstrated that the infection rate of 9 kinds of viruses in tissue culture plantlets was 0 . Therefore, this study could lay the foundation for the production of breed virus-free plantlets of "Guichang" kiwifruit.

\section{Conclusions}

In this study, the establishment of a tissue culture rapid propagation system of "Guichang" kiwifruit was carried out and then detected virus status via the RT-qPCR method. The tissue culture rapid propagation system proved that $\mathrm{MS}+6-\mathrm{BA}(1.0 \mathrm{mg} / \mathrm{L})+\mathrm{IBA}(0.2 \mathrm{mg} / \mathrm{L}), \mathrm{MS}+6-\mathrm{BA}(1.0 \mathrm{mg} /$ 
$\mathrm{L})+\mathrm{IBA}(0.1 \mathrm{mg} / \mathrm{L})$, and $1 / 2 \mathrm{MS}+\mathrm{IBA}(0.3 \mathrm{mg} / \mathrm{L})$ were the optimal induction, proliferation, and rooting mediums, respectively. In addition, the RT-qPCR results demonstrated that the infection rate of ASGV, CMV, AVX, CNV, RMV, CLBV, AcVB, PZSV, and CLRV in the tissue culture plantlets was 0 . This study could lay the foundation for the production of "Guichang" kiwifruit tissue culture plantlets and the industrial rapid propagation of plantlets.

\section{Data Availability}

The datasets used and analyzed during the current study are available from the corresponding author on reasonable request.

\section{Conflicts of Interest}

The authors declare that they have no conflicts of interest.

\section{Authors' Contributions}

Weimin Zhong and Junliang Zhou contributed equally to this work.

\section{Acknowledgments}

This work was supported by the Guizhou Province Science and Technology Plan Project Natural Science ([2016]2528), Agricultural Science and Technology Cooperation Projects of Guiyang City, Guizhou Academy of Agricultural Sciences ([2015]002), Foundation of Guizhou Province (LH[2014] 7710), and China Agriculture Research System of MOF and MARA.

\section{References}

[1] I. Nishiyama, Y. Yamashita, M. Yamanaka, A. Shimohashi, T. Fukuda, and T. Oota, "Varietal difference in vitamin C content in the fruit of kiwifruit and other Actinidia species," Journal of Agricultural and Food Chemistry, vol. 52, no. 17, pp. 5472-5475, 2004.

[2] S. Huang, J. Ding, D. Deng et al., "Draft genome of the kiwifruit Actinidia chinensis," Nature Communications, vol. 4, no. 1, p. 2640, 2013.

[3] F. L. Jin, M. Li, and C. M. Han, "Biological characteristic of Guichang Chinese gooseberry and its cultivation technique with high yield and quality in Qianbei areas," Guizhou Agricultural Sciences, vol. 31, pp. 1001-3601, 2003.

[4] R. C. Gardner, "Genetic engineering of kiwifruit," in Proceedings of the NZ kiwifruit Authority National Research Conference, pp. 27-28, Hamilton, New Zealand, December 1986.

[5] Y. Lv, "Main characteristics of Hongyang kiwifruit," Northwest Horticulture, vol. 3, pp. 37-38, 2001.

[6] J. Chai, Y. Gao, Y. Dong, L. Kong, and Y. Zhang, "Browning treatment in tissue culture of "hongyang" kiwifruit," IOP Conference Series: Materials Science and Engineering, vol. 452, Article ID 022075, 2018.

[7] X. H. Wu, Y. L. Zhang, and Y. Zhou, "Establishment of high frequency and direct regeneration system from leaf of "Hayward" kiwifruit [Actinidia deliciosa (A. Chev.) C. F.
Liang et A. R. Ferguson]," Plant Physiology Journal, vol. 49, pp. 759-763, 2013.

[8] X. P. Zhao, K. M. Luo, Y. Zhou, X. H. Wen, L. Yang, and S. H. Tang, "Establishment of high frequency regeneration via leaf explants of 'Red Sun' kiwifruit (Actinidia chinensis)," Chinese Journal of Biotechnology, vol. 29, pp. 1599-1606, 2013.

[9] F. Yu, "Establishment of tissue culture and rapid propagation system of kiwi," Chinese Horticulture Abstract, vol. 6, pp. 17-30, 2017.

[10] G. X. Gao, "Browning in plant tissue culture," Plant Physiology Communications, vol. 35, pp. 501-506, 1999.

[11] J. H. Wu, "Establishment of in vitro culture systems for breeding new types of kiwifruit and forActinidiagenomics studies," Acta Horticulturae, vol. 1224, pp. 195-202, 2018.

[12] A. G. Blouin, M. N. Pearson, R. R. Chavan et al., "Viruses of kiwifruit (Actinidia species)," Journal of Plant Pathology, vol. 95, pp. 221-235, 2013.

[13] A. G. Blouin, R. R. Chavan, M. N. Pearson, R. M. Macdiarmid, and D. Cohen, "Detection and characterisation of two novel vitiviruses infecting Actinidia," Archives of Virology, vol. 157, no. 4, pp. 713-722, 2012.

[14] Y. X. Wang, N. Hong, G. P. Wang, Z. K. Yang, L. P. Wang, and L. Li, "First report of the Tospovirus tomato necrotic spot associated virus infecting kiwifruit (Actinidia sp.) in China," Plant Disease, vol. 100, no. 12, p. 2539, 2016.

[15] D. Wang, X. X. Liu, T. T. Li et al., "First report of Cucumber mosaic virus infection in kiwifruit (Actinidia chinensis) in China," Plant Disease, vol. 102, no. 6, p. 1180, 2018a.

[16] Y. Zheng, B. Navarro, G. Wang et al., "Actinidia chlorotic ringspot-associated virus: a novel emaravirus infecting kiwifruit plants," Molecular Plant Pathology, vol. 18, no. 4, pp. 569-581, 2017.

[17] S. Veerakone, L. W. Liefting, J. Tang, and L. I. Ward, "The complete nucleotide sequence and genome organisation of a novel member of the family Betaflexiviridae from Actinidia chinensis," Archives of Virology, vol. 163, no. 5, pp. 1367-1370, 2018.

[18] H. Liu, S. Song, W. Wu et al., "Distribution and molecular characterization of Citrus leaf blotch virus from Actinidia in Shaanxi province, China," European Journal of Plant Pathology, vol. 154, no. 3, pp. 855-862, 2019.

[19] S. D. Card, M. N. Pearson, and G. R. G. Clover, "Plant pathogens transmitted by pollen," Australasian Plant $\mathrm{Pa}$ thology, vol. 36, no. 5, pp. 455-461, 2007.

[20] H. Ma, Studies on Tissue Culture and Rapid Propagation of Kiwifruit Seedlings, Anhui Agricultural University, Hefei, China, 2015.

[21] D. P. Wang, "The effect of hormone combination with different concentrations on the callus induction and bud differentiation of kiwifruit," Journal of Anhui Agricultural Sciences, vol. 35, pp. 11761-11821, 2007.

[22] H. M. Yu, M. Z. Zhao, Y. M. Qian, J. Wang, J. Xia, and F. H. Pang, "Tissue culture and rapid propagation of bud stem segments of kiwifruit in Heyward," Jiangsu Agricultural Sciences, vol. 42, pp. 78-79, 2014.

[23] Q. J. Long, Y. J. Wu, and M. Xie, "Tissue culture and rapid propagation of "Hongyang" kiwifruit leaves and bud stem segments," Acta Agriculturae Zhejiangensis, vol. 22, pp. 1004-1524, 2010.

[24] M. Irshad, B. He, S. Liu et al., "In vitro regeneration of Abelmoschus esculentus L. cv. Wufu: influence of anti-browning additives on phenolic secretion and callus formation frequency in explants," Horticulture, Environment, and Biotechnology, vol. 58, no. 5, pp. 503-513, 2017. 
[25] D. Rani and P. K. Dantu, "Sustained shoot multiplication and method for overcoming in vitro browning in medicinally important plant, Piper chaba Hunt," Proceedings of the National Academy of Sciences, India Section B: Biological Sciences, vol. 86, no. 2, pp. 407-413, 2016.

[26] I. Verstraeten and D. Geelen, "Adventitious rooting and browning are differentially controlled by auxin in rootingrecalcitrant Elegia capensis (Burm. f.) Schelpe," Journal of Plant Growth Regulation, vol. 34, no. 3, pp. 475-484, 2015.

[27] P. Bhattacharyya, S. Kumaria, and P. Tandon, "High frequency regeneration protocol for Dendrobium nobile: a model tissue culture approach for propagation of medicinally important orchid species," South African Journal of Botany, vol. 104, pp. 232-243, 2016.

[28] M. X. Gao, X. Feng, R. L. Lai, W. G. Chen, and Y. T. Chen, "Optimization of tissue culture system of Actinidia deliciosa cv," "Miliang-1". Southeast Horticulture, vol. 4, pp. 1-5, 2017.

[29] L. Kong, R. Wang, Q. Song, Y. Xie, and Y. Zhang, "Establishment of rapid propagation system of "xu Xiang" kiwifruit," IOP Conference Series: Earth and Environmental Science, vol. 252, no. 5, Article ID 052027, 2019.

[30] R. Wang, D. Zhou, J. Luo, and J. B. Fang, "Progress report on viruses of kiwifruit," Journal of Fruit Science, vol. 34, pp. 1043-1050, 2017.

[31] Y. Z. Zheng, G. P. Wang, J. F. Zhou et al., "The detection of Actinidia virus $A$ and Actinidia virus $B$ by RT-PCR and their molecular variation analysis," Acta Horticulturae Sinica, vol. 42, pp. 665-671, 2015. 